\title{
On the Translaminar Fracture Toughness of Vectran/Epoxy Composite Material
}

\author{
S. I. B. Syed Abdullah, L. Iannucci, E. S. Greenhalgh \\ Department of Aeronautics, Imperial College London, Exhibition Road, London SW7 2AZ, \\ UK \\ Corresponding Author Email: s.syed-abdullah14@imperial.ac.uk
}

\begin{abstract}
The mode I fracture toughness associated with fibre tensile failure was investigated for a Vectran/MTM57 composite system. A modified compact tension specimen was designed and manufactured to mitigate compressive and buckling failure due to the low compressive properties which are an inherent characteristic of Vectran fibres. On average, the mode I translaminar fracture toughness for Vectran/MTM57 was found to be approximately 130 - 145 $\mathrm{kJ} / \mathrm{m}^{2}$ for initiation and $250-260 \mathrm{~kJ} / \mathrm{m}^{2}$ for propagation. In contrast with other composite systems such as carbon and glass fibre, the fracture toughness of Vectran/MTM57 was found to be relatively higher, with up to $48.26 \%$ and $95.27 \%$ for initiation and propagation, respectively for some carbon fibre composite system; $9.93 \%$ and $68.6 \%$ for initiation and propagation, respectively for S2-Glass/epoxy system.
\end{abstract}

Keywords: Compact Tension (CT), Translaminar Fracture Toughness, Mode I, Fractography

\section{Introduction}

In the past decade, the use of composite materials such as Carbon Fibre Reinforced Polymer (CFRP) and Glass Fibre Reinforced Polymer (GFRP) in industrial applications have shown significant increase due to its attractive properties, such as high strength-to-weight ratio and good corrosion resistance. The Boeing 787 Dreamliner, and its European counterpart, the 
Airbus A350 XWB have both used more than $50 \%$ of composite materials in its aircraft structure. However, its susceptibility to many forms of operational threats, such as low and high velocity impact are one of the most prominent issues relating to structural design involving composite materials. Therefore, there is a greater need to understand the behaviour of these materials, especially factors influencing failure. During impact situations, many forms of damage such as matrix cracking, delamination and fibre fracture may be present. Each type of damage dissipates energy and therefore dictates the performance of a composite material in impact situations. For instance, GFRP may perform better in low velocity impact situations if compared to CFRP due to its higher delamination resistance [1]. Although the tensile strength and stiffness of glass fibres are generally lower (due to the presence of surface flaws during processing [2]) compared to that of glass fibres $(68.5 \%$ and $11.35 \%$ higher respectively for stiffness and strength ${ }^{1}$ [3] [4]), the tensile strain-to-failure of S2-Glass fibres generally outperforms CFRP by at least three times $\left(1.9 \%\right.$ and $5.7 \%$ for CF and Glass, respectively $\left.{ }^{1}\right)$ [3] [4]. Furthermore, the poor fibre matrix bonding in glass fibre composites generally meant an increase in the delamination toughness (due to the promotion of fibre bridging as a toughening mechanism [1]),

It is generally understood that the final failure of composite materials often involves fibre failure. This is because energy dissipation in fibre failure is normally two to three orders of magnitude larger than that of the other damage modes (delamination, matrix cracking, etc.) [5] Thus, fracture toughness characterisation of fibre failure, on top of the other damage modes mentioned previously, is cornerstone to obtain a clear view of the material behaviour. By doing so, not only the overall energy absorption capabilities are obtained, but rather a comprehensive understanding of the mechanism contributing to the fracture toughness of the material, such as fibre pull-out, delamination, or fibre bridging [2] can be achieved. For example, the

\footnotetext{
${ }^{1}$ IM7 carbon fibre and S2-Glass fibre
} 
contribution of fibre pull-out in the fracture toughness of CFRP is the highest, due to the interfacial sliding (shear) happening between the fibre and matrix, before completely detaching the fibre from its socket [5] [6] [7]. Besides fibre pull-out, fibre-matrix debonding has also been reported by many researchers [5] [6] [8] [9] to account for a high energy dissipation thus contributing to a high fracture toughness value. The influence of lay-up have also been studied, specifically on CFRP by many researchers [7] [9], and have concluded that although the layup may have an influence on the propagation values, the initiation values were found to be almost independent of the layup. Table 1 shows some of the fracture toughness values of CFRP available in the open literature.

Table 1: Tensile fibre breaking study in the open literature

\begin{tabular}{ccccc}
\hline Study & $\begin{array}{c}\text { Material } \\
\text { system }\end{array}$ & $\begin{array}{c}\text { Initiation } \\
\left(\mathbf{k J} / \mathbf{m}^{\mathbf{2}}\right)\end{array}$ & $\begin{array}{c}\text { Propagation } \\
\mathbf{( \mathbf { k J } / \mathbf { m } ^ { 2 } )}\end{array}$ & $\begin{array}{c}\text { Ply } \\
\text { architecture/Layup }\end{array}$ \\
\hline Pinho et al [8] & T300/913 & 91.6 & 133 & UD/ Cross-Ply \\
\hline Laffan et al. [6] & IM7/8552 & 112 & 147.2 & UD/ Cross-Ply \\
\hline Teixeira et al. [7] & T800s/M21 & 152 & 237 & UD/ Cross-Ply \\
\hline Catalanotti et al. [10] & IM7/8552 & 97.8 & 133.3 & UD/ Cross-Ply \\
\hline Bullegas et al [11] & TR50s/K51 & 29.5 & 32.2 & UD/ Cross-Ply
\end{tabular}

Although significant research has been performed on the characterisation of tensile (mode I) translaminar fracture toughness of CFRP, little to no research can be found on the mode I translaminar fracture toughness of other types of material, especially polymer based fibre composites. One of the major problem in characterising the mode I translaminar fracture toughness of polymer fibre based composites is due to its low compressive properties which is generally less than $10 \%$ of its tensile properties [12]. The low compressive properties could ultimately lead to buckling and compressive failure of the test specimen, therefore invalidating the laws of Linear Elastic Fracture Mechanics (LEFM) [13]. Also, the high tensile strain-to- 
failure of polymeric fibres generally meant compressive failure may occur at the back of the specimen, before any crack propagation could even occur. Recently, Katafiasz et al. [14] investigated the mode I translaminar fracture toughness of S2-Glass/MTM57 composite laminates and found the $G_{I C}$ to be $131.9 \mathrm{~kJ} / \mathrm{m}^{2}$ and $154.2 \mathrm{~kJ} / \mathrm{m}^{2}$ for initiation and propagation, respectively. A modified CT specimen was utilised to mitigate compressive and buckling failure when measuring the $G_{I C}$ for S2-Glass/MTM57 laminates. To date, no other research has been performed in characterising tensile fracture toughness of polymer fibres, except for Mai et al. [15] in characterising fracture toughness of Kevlar 49/epoxy composite.

In this work, the mode I translaminar fracture toughness of Vectran/MTM57 will be investigated using a modified CT specimen. Vectran is a Thermotropic Liquid Crystal Polymer (TLCP) based fibre which possesses similar mechanical behaviour to Kevlar fibres. Vectran fibres possess a high tensile strength, stiffness, and tensile strain-to-failure ratio - properties

which are highly desirable in ballistic protection materials. However, as in the case of many polymers such as UHMWPE and PET, the low compressive strength and stiffness of Vectran fibres (generally around 10\% its tensile strength and stiffness) often create difficulties during fracture toughness characterisation - both interlaminar and translaminar. Therefore, a modified CT specimen originally designed by Katafiasz et al. [14] will be utilised to measure the mode I translaminar fracture toughness of the composite. Scanning Electron Microscope (SEM) analysis will then be performed post-failure to understand the type of damage that occurs on the composite material.

\section{Model development in Finite Element}

Initial design from Katafiasz et al. [14] were utilised and further developed for use in this research. The model consists of two discrete parts making up the final specimen; the thick part, Figure 1 (a), and the thin part, Figure 1 (b). Figure 1 (c) shows the exploded view of the final 
CT specimen, in which the thin part is sandwiched between two thick parts, and crack is expected to grow along the dashed line shown in Figure 1 (b).

The non-linear explicit Finite Element Method (FEM) package, LS-Dyna was utilised in numerical modelling of the CT specimen. Initially, only the thin part is modelled, using thick shells, with 4 through-thickness integration points in each element. However, as expected, buckling at the rear of the specimen was seen even before any mode I crack could propagate; shown in Figure 2. Therefore, the thick part was gradually added to mitigate any undesirable failures such as compressive or buckling failures. The thick part was added in $1 \mathrm{~mm}$ interval, at both side of the thin part at each time. The final FE model consists of 236,156 thick shell elements with six through-the-thickness integration points in each element. No cohesive elements were included in the model to reduce the computational time. A mesh sensitivity study was employed using the CT specimen to be modelled, where the total internal energy was made as a function of the element size. The global mesh size on the specimen was set to be $1 \mathrm{~mm}$, and the elements around the crack tip were set to $0.5 \mathrm{~mm}$. The internal energy was found to converge at an element size of $0.5 \mathrm{~mm}$, quantified as a convergence of $0.073 \%$ upon reaching the contact stress of approximately $800 \mathrm{MPa}$ (equivalent to the tensile strength of Vectran/MTM57). A tiebreak contact criterion was employed in the model (shown in Figure 2), which corresponds to the tensile strength of Vectran/MTM57. The tiebreak criterion, or cohesive surfaces algorithm, is commercially available in LS-Dyna in which users supply the threshold contact strength, and the tiebreak criterion were modelled as discrete linear springs, which would then fail if the failure criterion defined below is met [16]:

$$
\frac{\sigma_{n}}{N F L S} \geq 1
$$

where $\sigma_{n}$ is the normal failure stress and NFLS is the normal failure stress (input from user; in this case, the tensile strength at failure for Vectran/MTM57). Upon failure, the nodes that are initially tied will detach, emulating crack propagation observed experimentally. 


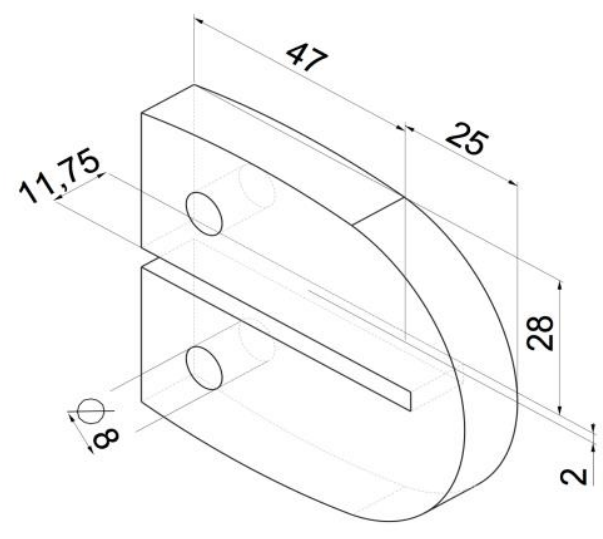

(a)

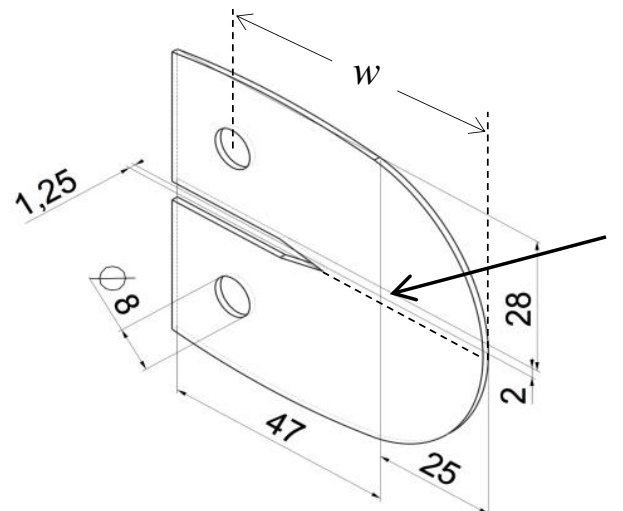

Dashed line representing expected/desired crack propagation path

(b)

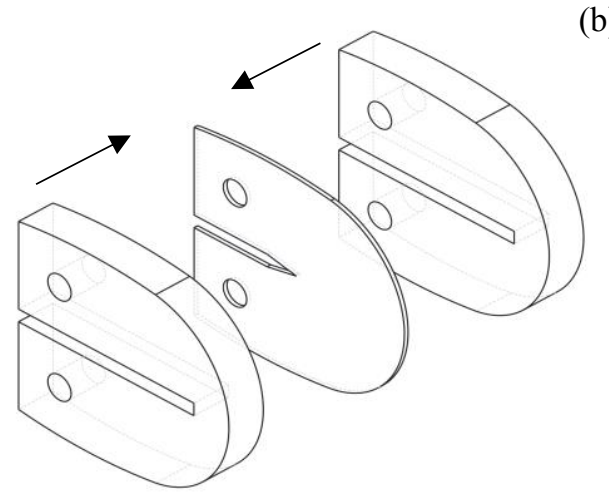

(c)

Figure 1: (a) Thick part of the specimen (b) Thin part of the specimen (c) Exploded view. Dimensions are in $\mathrm{mm}$.

The boundary condition that was applied in the simulation was similar to that of the actual testing, in which the bottom pin is fixed, whilst applying a ramped displacement vs time load, to avoid any inertial effects.

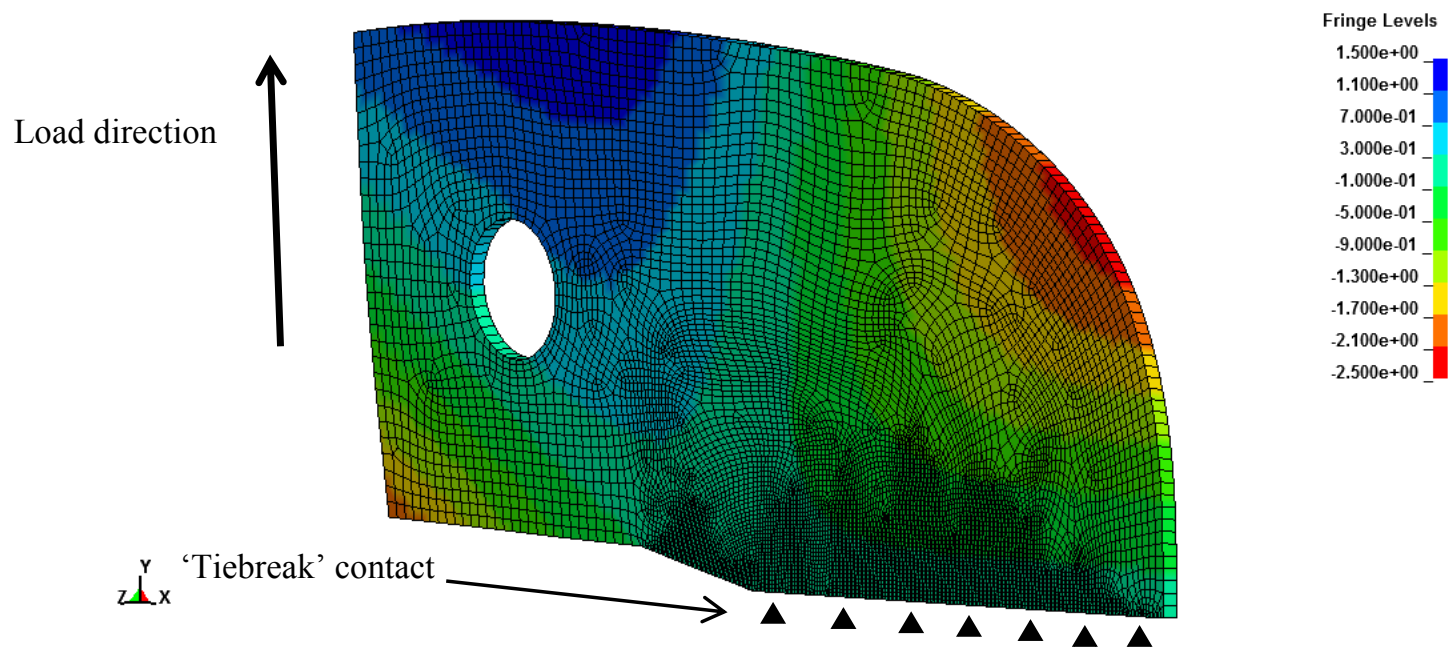

Figure 2: CT specimen modelled with LS-Dyna, utilising symmetry. Contours represent the out-of-plane displacement (units in $\mathrm{mm})$. Small dark triangles represent the 'tiebreak' contact used in the simulation 


\section{Materials and manufacturing}

Cross-ply $\left(0^{\circ} / 90^{\circ}\right)$ Non-Crimp Fabric (NCF) Vectran (313 gsm) with polyester stitches supplied by Sigmatex was laid up with Hexcel MTM57 toughened epoxy resin film (212 gsm). Specimen manufacture involves 24 sets of three Vectran NCF fabric $(250 \mathrm{~mm}$ x $250 \mathrm{~mm})$ with two MTM57 resin films sandwiched in between were stacked (stacking sequence: $\left[0^{\circ} / 90^{\circ}\right]_{38 s}$ ). On each set, rectangular cuts were made using a round-tip scalpel, and shown in Figure 3. For the thin crack growth region, two MTM57 resin film were placed in between four plies of Vectran NCF fabric, resulting in a cured thickness of approximately $1.25 \pm 0.1 \mathrm{~mm}$. On each stacked set of Vectran fabric and MTM57 resin films, blue 'flash' tape was placed around the stacked plies to ensure minimal movements of Vectran yarns during lay-up and curing. Finally, L-Shaped PTFE inserts were placed into the rectangular 'grooved' section before curing. The fibre volume fraction was $62 \%$, measured via fibre counting method using an optical microscope [17] [18]. The number of fibres in each tow was counted and correlated with the weight of $1 \mathrm{x} 1 \mathrm{~cm}^{2}$ of Vectran/MTM57 ply, excluding the contribution of the polyester stitches to the fabric (measured to be approximately $6.2 \%$ of the total volume of the composite). 


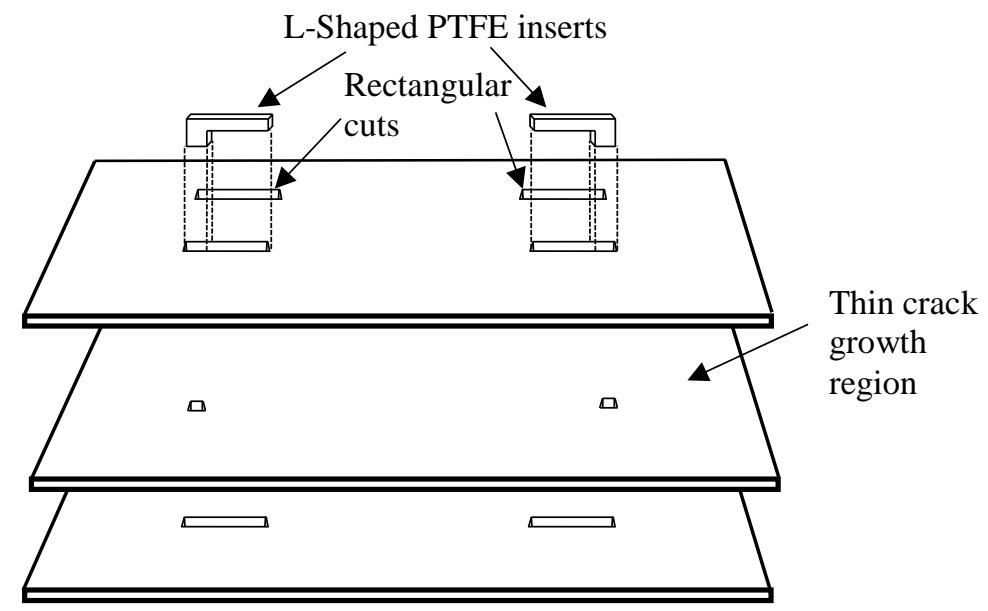

(a)

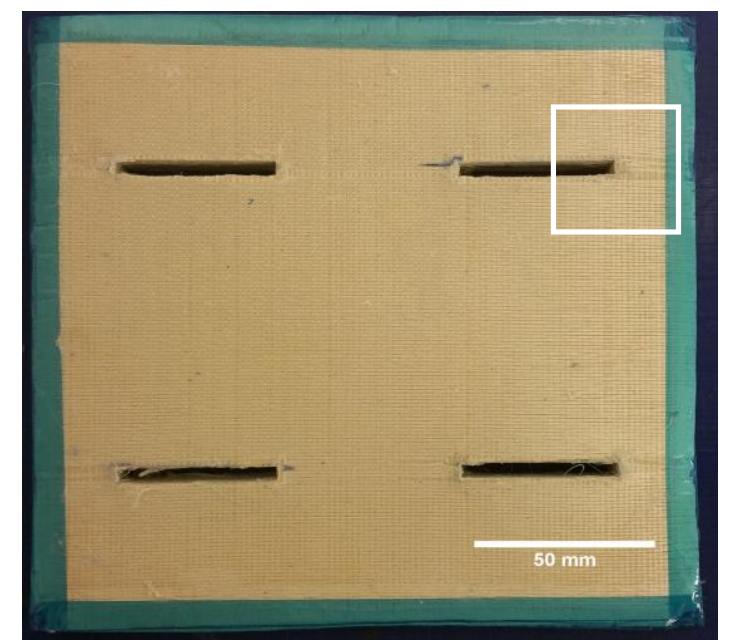

(b)

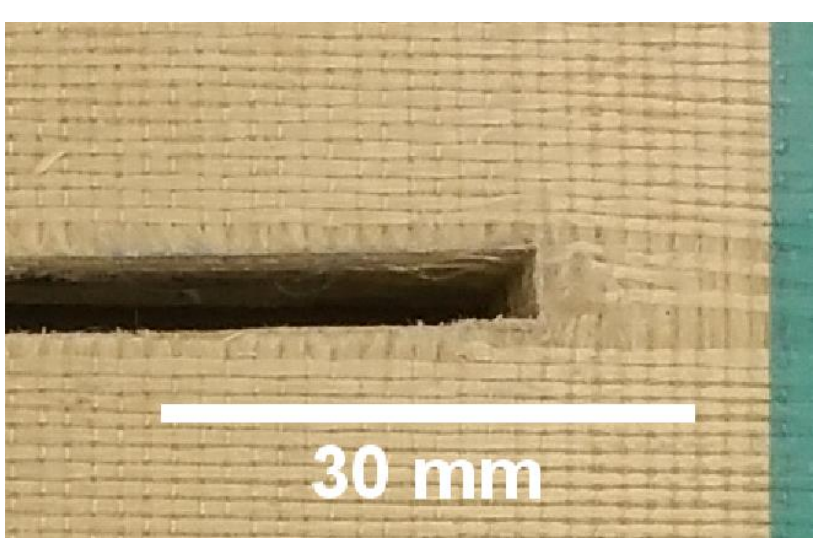

(c)

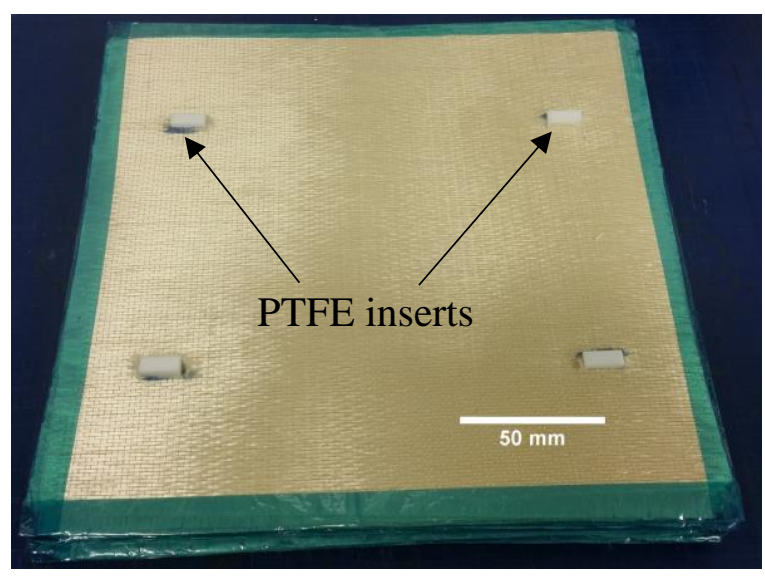

(d)

Figure 3: (a) Exploded view on the layup for Vectran/MTM57 CT specimen (b) Rectangular cuts (grooves) on the uncured laminates. (c) Close up image on white square found in Figure 3 (a). (d) Uncured laminates with PTFE inserts

After curing, the laminate was cut into dimensions shown in Figure 1. The thin crack growth region was then cut into the final shape as seen in Figure 1 (b) using a diamond saw cutter, subsequently removing the PTFE inserts placed earlier. It must be noted that due to the fibrillar 
nature of Vectran fibres, residual 'floss' were produced when using the diamond coated disc saw. However, it was assumed that the residual 'floss' will not interfere with the $G_{I c}$ measurement since it was far away from the crack tip.

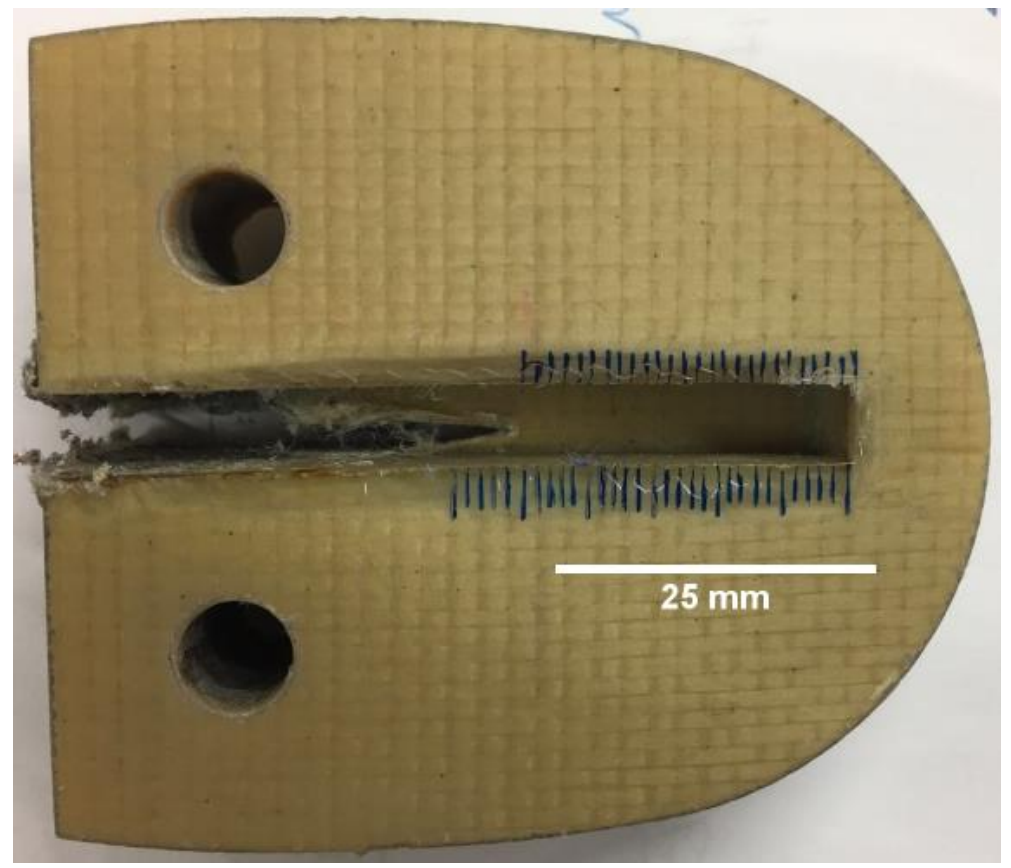

(a)

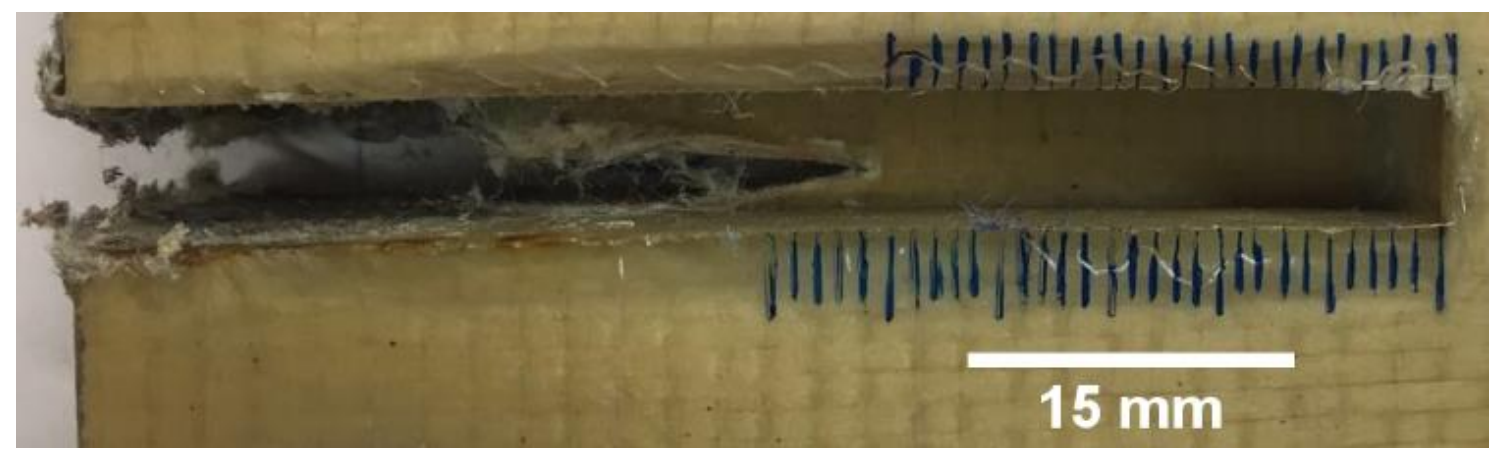

(b)

Figure 4: Actual CT specimen used during testing

\section{Test method and experimental setup}

The CT testing was performed at room temperature $\left(20^{\circ} \mathrm{C}\right)$ using an Instron universal testing machine (Instron 5969 with a load cell capacity of $50 \mathrm{kN} ; 0.5 \%$ measurement accuracy). The specimens were loaded in tension with a displacement controlled rate of $0.5 \mathrm{~mm} / \mathrm{min}$. An 
Imetrum Optical strain measurement system was employed to measure the machine cross-head displacement as well as a video capture to monitor the crack growth at $10 \mathrm{~Hz}$ (10 data points per second). The Microbeam 512 (5,293 Lux at 1 meter, 95 CRI) LED lighting were used to improve visualisation for video recording.

\section{Data Reduction}

There are several data reduction methods which are commonly used to obtain the mode I translaminar fracture toughness. Depending on suitability and convenience, one or more data reduction method can be used to obtain the $G_{I c}$ of a composite material. Sub-sections below briefly discuss on some of the most common data reduction method that have been used to obtain the mode I $G_{I c}$ of composite materials. In this study, the Area Method (AM), Compliance Calibration (CC), and the Modified Compliance Calibration (MCC) method were chosen to calculate the $G_{I c}$ of Vectran/MTM57.

\subsection{ASTM E399}

The ASTM E399 testing standard [19], valid for isotropic metals, gives the stress intensity factor, $K_{I c}$, as:

$$
K_{I c}=\frac{P_{c}}{t \sqrt{w}} f\left(\frac{a}{w}\right)
$$

where $P_{c}$ was the critical load which causes fracture, $t$ was the specimen thickness, $w$ was the width of the specimen, measured from the load line to the right hand edge of the specimen (shown in Figure $1(\mathrm{~b}))$, and $f\left(\frac{a}{w}\right)$ is a function which relates crack length with the specimen geometry. Finally, $G_{I c}$ can be obtained from the critical stress intensity factor as [8]:

$$
G_{I c}=\frac{K_{I C}^{2}}{\sqrt{2 E_{11} E_{22}}} \sqrt{\sqrt{\frac{E_{11}}{E_{22}}}+\frac{E_{11}}{2 G_{12}}-v_{12}}
$$


where $E_{11}$ is the elastic modulus in the longitudinal direction, $E_{22}$ is the elastic modulus in the transverse direction, $G_{12}$ is the shear modulus, and $v_{12}$ is the major Poisson's ratio.

\subsection{Area Method}

The area method is among the simplest methods in calculating the $G_{I c}$ and is given by equation (4) below:

$$
G_{I c}=\frac{1}{2 t \Delta a}\left(P_{1} d_{2}-P_{2} d_{1}\right)
$$

where $t$ was the thickness of the specimen, $\Delta a$ was the change in crack length, $P_{1}, P_{2}, d_{1}$, and $d_{2}$ are the loads and displacements observed from the load-displacement curve, and was represented in Figure 5. Essentially, the $G_{I c}$ was the area under the shaded curve, excluding the elastic component of the curve (which can be associated with other crack points).

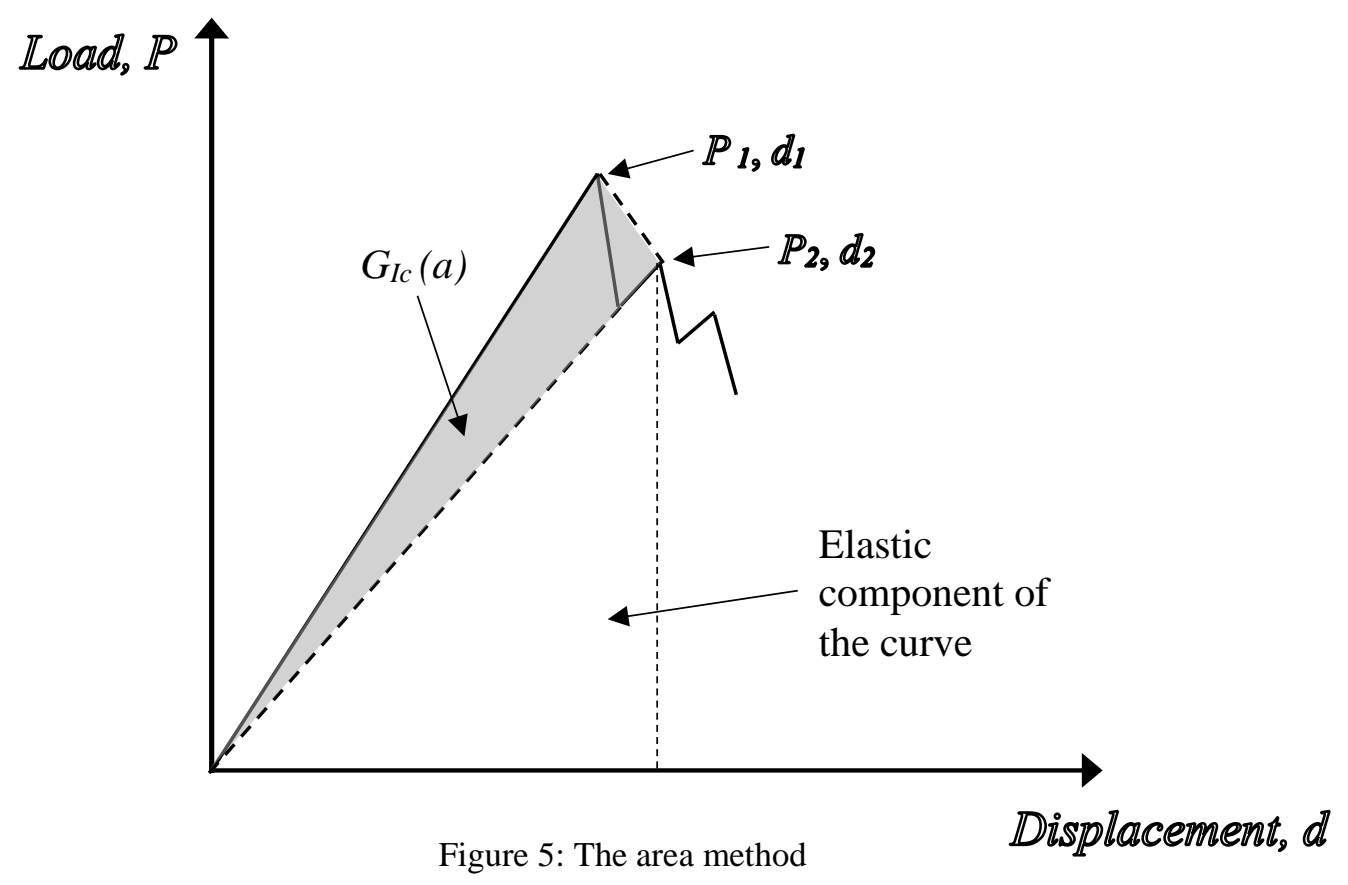

\subsection{Compliance Calibration (CC)}

The $G_{I c}$ can also be calculated using the change of compliance, $C$, with the experimentally obtained crack length, $a$, given by (5) [6]: 


$$
G_{I c}=\frac{P_{c}^{2}}{2 t} \frac{d C}{d a}
$$

where $C$ was the experimentally observed compliance given by:

$$
C=\frac{d_{c}}{P_{c}}
$$

where $d_{c}$ and $P_{c}$ are the critical cross-head displacement and load, respectively, at specific crack lengths. For this study, the experimental $C$ vs $a$ data was plotted in Figure 6 and a curve fit with a function given by [6]:

$$
C=(\alpha a+\beta)^{\gamma}
$$

where $\alpha, \beta, \gamma$ are determined by fitting equation (7) with experimentally obtained $C$ vs $a$ curve. The $G_{I C}$ can then be calculated from the following expression [6]:

$$
G_{I c}=\frac{P_{c}^{2}}{2 t} \cdot \alpha \gamma(\alpha a+\beta)^{\gamma-1}
$$

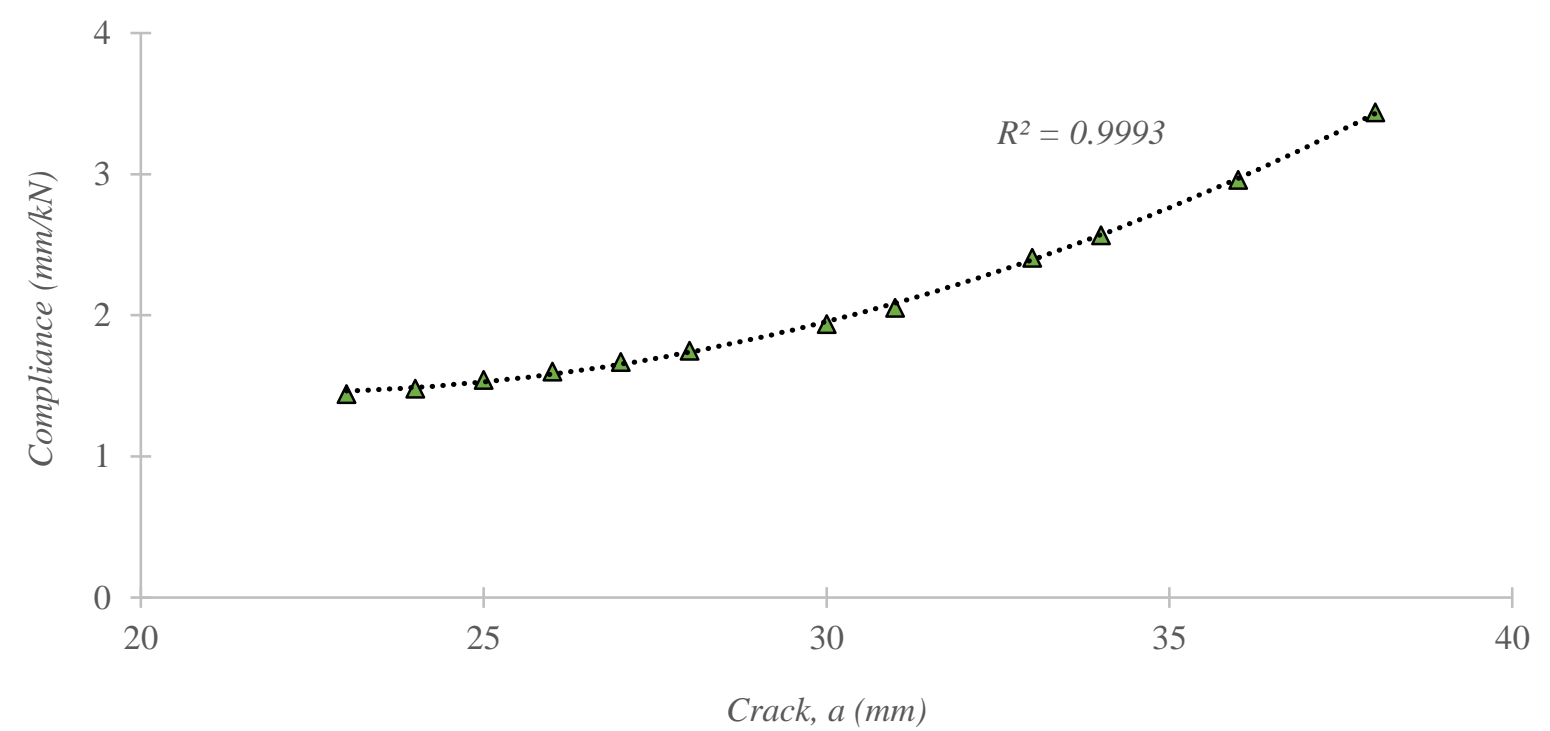

Figure 6: Typical compliance vs crack length curve obtained from the $\mathrm{CC}$ method 


\subsection{Modified Compliance Calibration (MCC)}

Compared to the $\mathrm{CC}$ method, the $\mathrm{MCC}$ method does not require the elastic compliance to be calculated at visually obtained crack length. Instead, the elastic compliance of the CT specimen was measured at various known crack length. In this study, the MCC method was utilised to calculate the fracture toughness of Vectran/MTM57, and the elastic compliance was obtained by using FE. The compliance vs crack length curve, similar to Figure 6 was plotted and fitted using equation (7). The $G_{I c}$ can then be calculated using equation (8)

\subsection{Fibre Tensile Failure}

Determination of the $G_{I c}$ associated with fibre tensile failure can be made using a rule of mixture-based relationship which accounts for the fractions of each constituents in the composites. Consider a Representative Unit Cell (RUC) for Vectran/MTM57 shown in Figure

7. The composite volume can be calculated using the rule of mixture based relationship for a cross-ply laminate given by:

$$
V_{c}=0.5 v_{f} V_{f}+\left(1-v_{f}-v_{s}\right) V_{m}+\left(1-v_{f}-v_{m}\right) V_{s}
$$

where $v_{f}$ and $V_{f}$ are the fibre volume fraction and fibre volume, respectively, $v_{m}$ and $V_{m}$ are the matrix volume fraction and matrix volume, respectively, and $v_{S}$ and $V_{S}$ are the stitch volume fraction and stitch volume, respectively. By using the ratio of volume between each of the constituents and the whole composites, equation (9) can be extended to include the fracture toughness for each constituent, given by:

$$
G_{I c}^{0}=2 \frac{\left(V_{c} G_{I c}^{\text {lam }}+V_{m} G_{I c}^{\text {mat }}+V_{s} G_{I c}^{\text {stitch }}\right)}{V_{f}}
$$




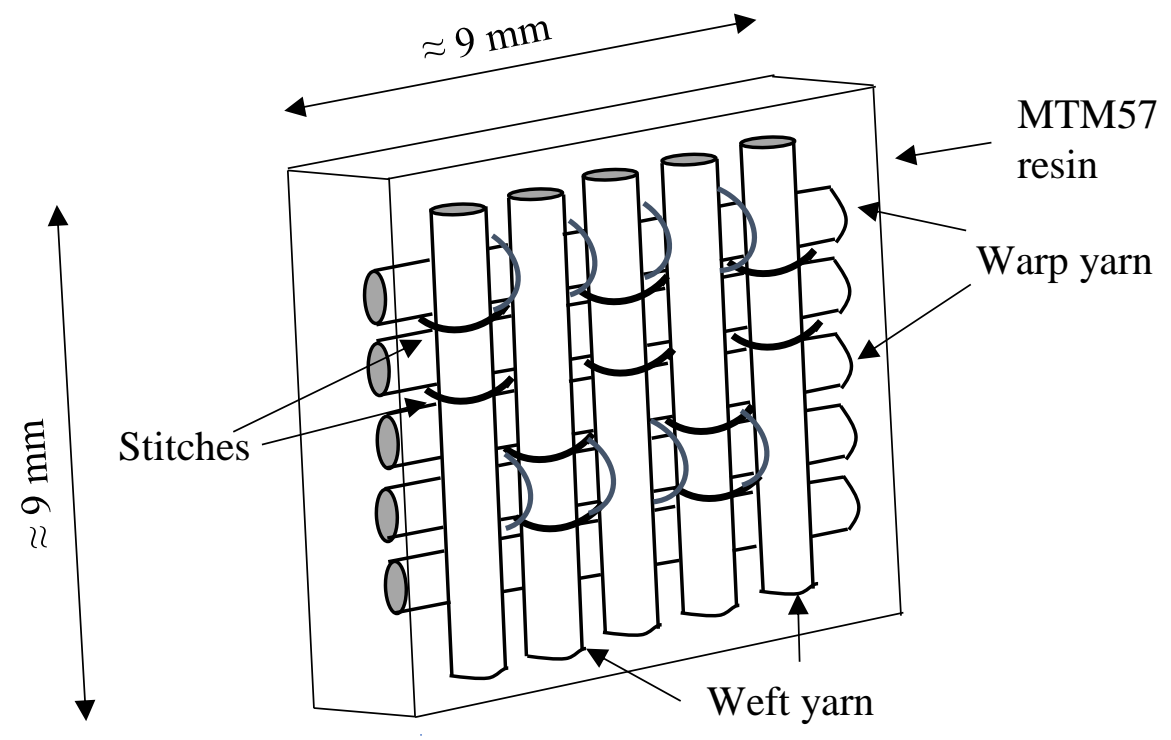

Figure 7: Representative unit cell for Vectran/MTM57

Finally, the fracture toughness for the polyester stitches can be determined using the suggestion by Irwin that combines fracture mechanics and inelastic deformation. Consider the relation between the critical stress intensity factor, $K_{I}$, and the fracture toughness, given by [13]:

$$
G_{I}=\frac{K_{I}^{2}}{E}
$$

where $E$ is the fibre tensile stiffness, and $K_{I}$ is given by:

$$
K_{I}=\sigma_{f} \sqrt{\pi a}
$$

where $\sigma_{f}$ was the fracture strength of the fibre, and $a$ was the half crack length. Substituting equation (12) into equation (11), $G_{I}$ can be re-written as [20]:

$$
G_{I}=\frac{\sigma_{f}^{2} \pi a}{E}
$$

\section{Results}

All three CT specimens exhibited a stick-slip fracture growth during testing. Due to the recorded video (using Imetrum optical strain system), the crack growth was recorded for every one $\mathrm{mm}$, up to $15 \mathrm{~mm}$ of growth. Figure 8 presents a typical load-displacement curve for Vectran/MTM57. Also in Figure 8, a typical Mode I load-displacement curve for CFRP was 
shown for comparison purposes. The elastic compliance, $C$, was measured directly from the load-displacement curve shown in Figure 8, and the R-curve obtained from the three different data reduction methods, Area Method, CC, and MCC are shown in Figure 9, Figure 10, and Figure 11 respectively. The average $G_{I c}$ obtained via the area method for initiation was 130.64 $\mathrm{kJ} / \mathrm{m}^{2}$ (CV: $7.22 \%$ ) while the average $G_{I c}$ obtained for propagation was $259.98 \mathrm{~kJ} / \mathrm{m}^{2}$ (CV: 9.17 $\%$ ). Consequently, the average $G_{I c}$ obtained using the CC method was $142.19 \mathrm{~kJ} / \mathrm{m} 2$ (CV: 6.01 $\%)$ and $262.68 \mathrm{~kJ} / \mathrm{m}^{2}(\mathrm{CV}: 9.47 \%)$ respectively for initiation and propagation.

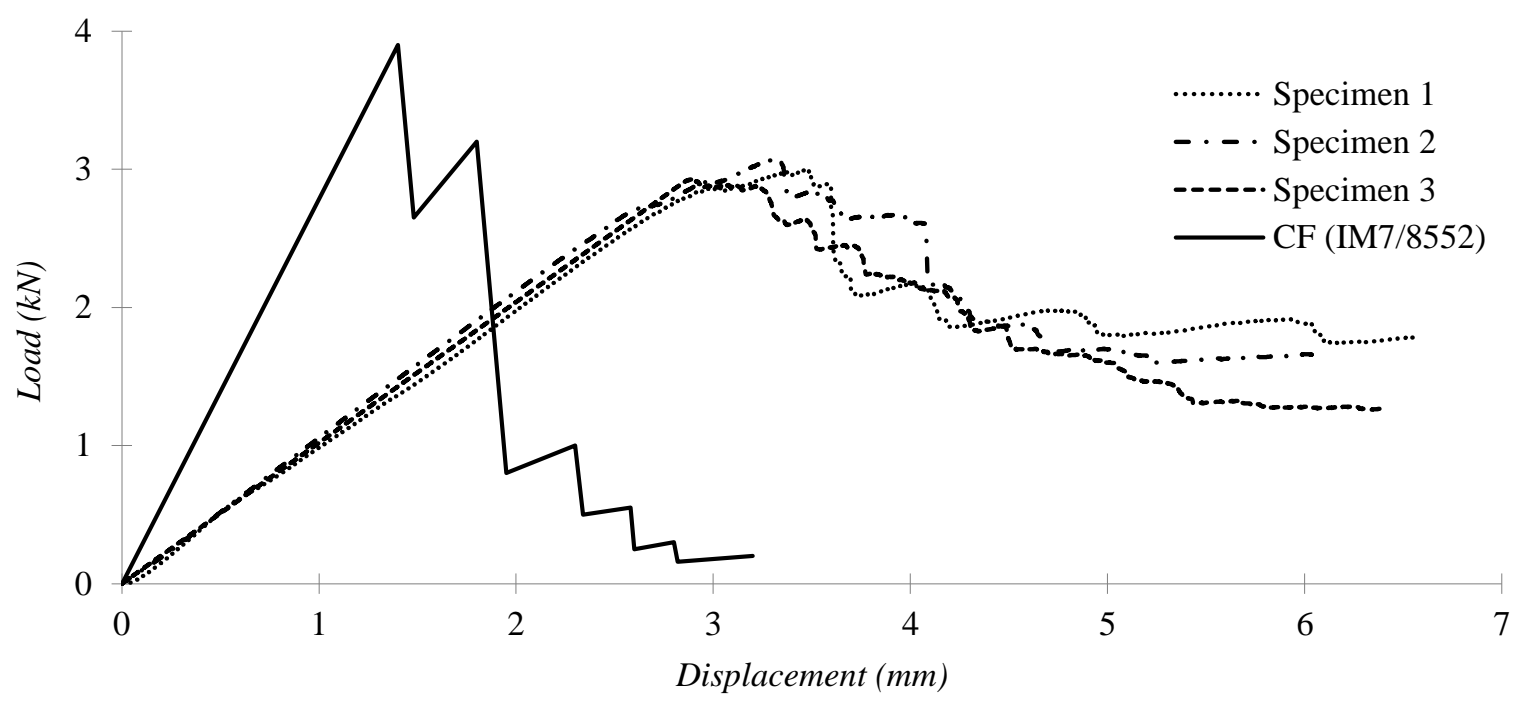

Figure 8: Load-Displacement curves for all three Vectran/MTM57 CT specimens and a typical loaddisplacement response for Mode I CT test of CF. 


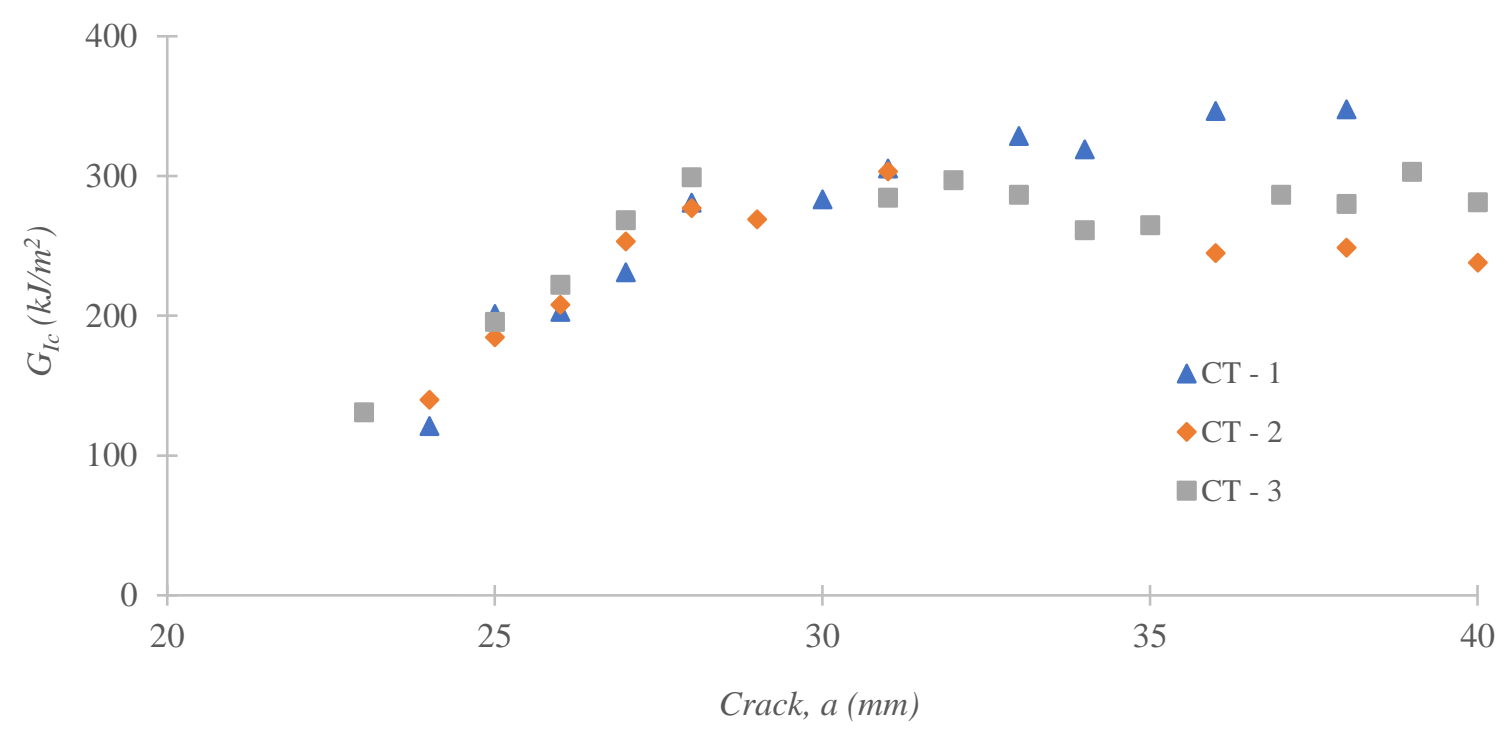

Figure 9: R-curve deduced by area method for all three Vectran/MTM57 specimens

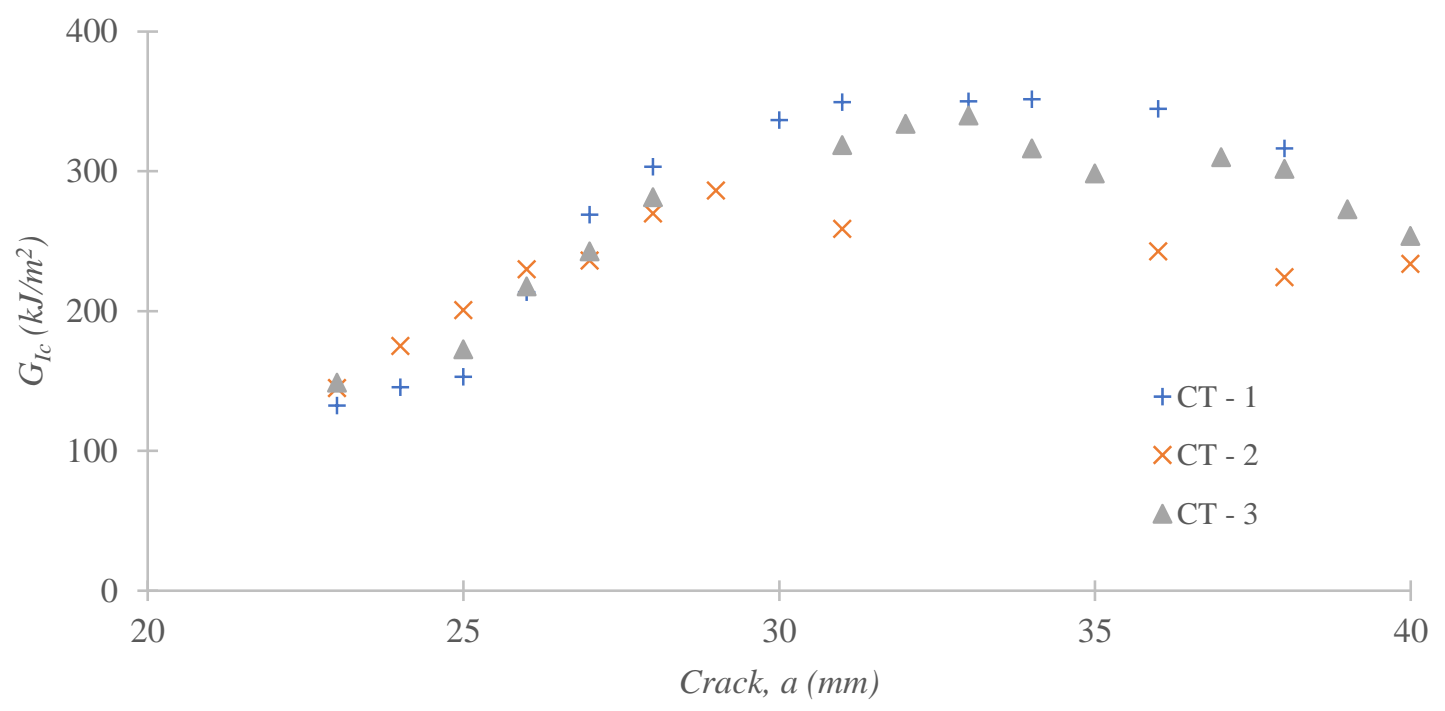

Figure 10: R-curve deduced by the CC method for all three Vectran/MTM57 specimens 


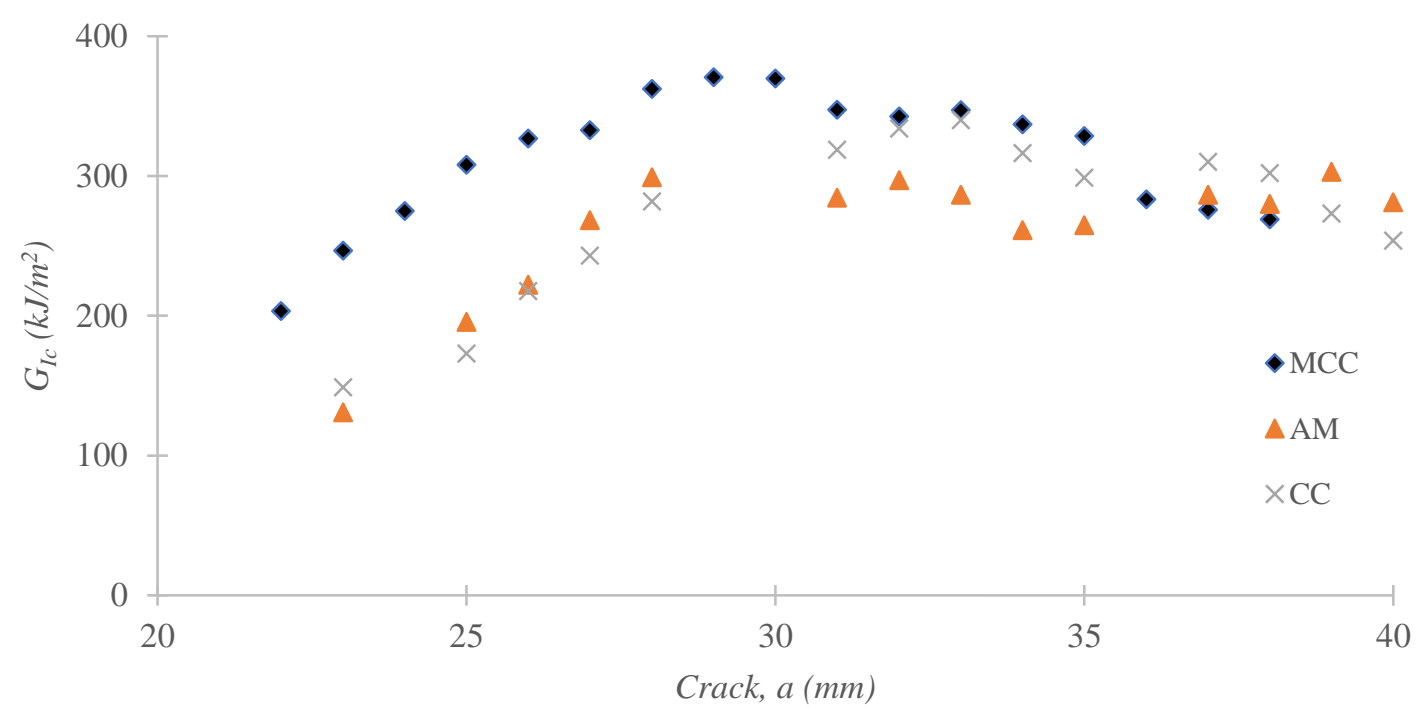

Figure 11: R-curve deduced by the MCC method using FE

\section{Discussions}

A fairly high $G_{I c}$ was obtained from the CT tests for Vectran/MTM57. This can be associated with several factors mainly:

a. It can be seen from Figure 8 that a higher cross-head travel (vertical displacement) is required to initiate and propagate the crack in Vectran/MTM57 laminate, compared to IM7/8552. This is since Vectran/MTM57 possesses a higher tensile strain-to-failure if compared to IM7/8552 - Figure 12. Also noticeable from Figure 12 was the residual plastic strain obtained from a cyclic load-unload quasi-static tensile test of the composite. This suggests a small energy contribution from the plastic deformation of the fibres;

b. Fibre pull-out - potentially the most significant source of fracture energy for most fibre composites may be traced back to the energy contribution from fibre pull-out [15] [21] [22] [23]. Following this, much work have been devoted into maximising the energy contribution from fibre pull-out by improving the interfacial shear strength between the fibre and the matrix. 


\subsection{Vectran fibre failure}

The nature of some polymeric fibres may exhibit some form of plastic deformation (permanent plastic strain), in which upon reloading, a finite amount of permanent plastic strain may be observed from the stress-strain curve. Figure 12 shows the tensile stress-strain curve for Vectran/MTM57 laminate. A clear slope increase can be seen between strain values of $1 \%$ and $1.5 \%$, often associated with the cold-drawing process of the polymeric macromolecules during a tensile test [24] [25]. Also shown in Figure 12 is the permanent plastic strain obtained from a cyclic loading-unloading tensile test on Vectran/MTM57 laminates.

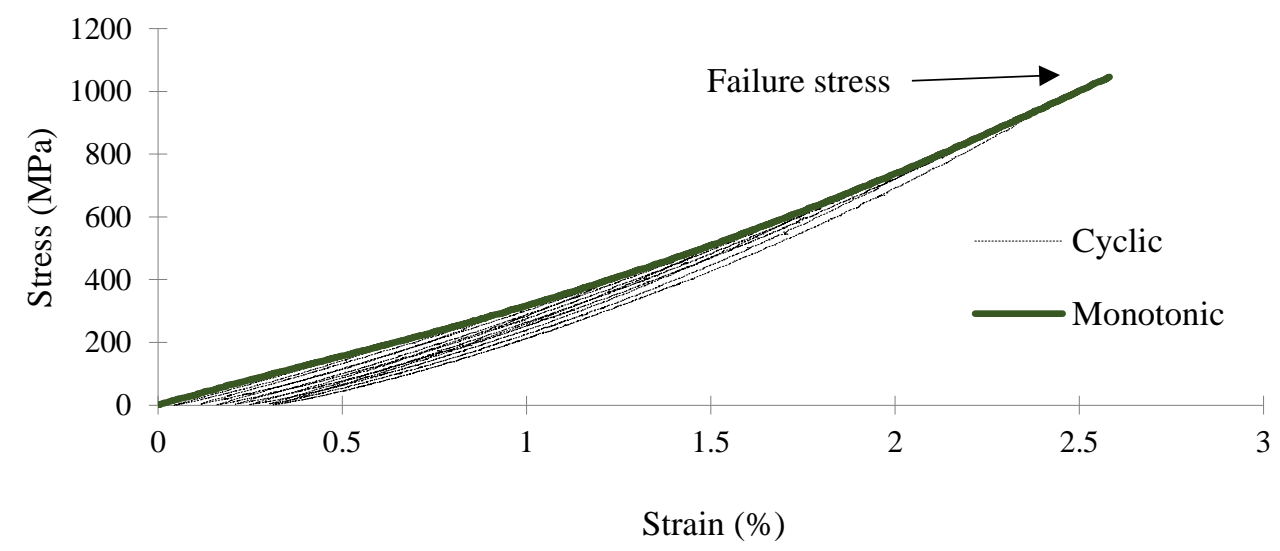

Figure 12: Tensile stress-strain curve for Vectran/MTM57

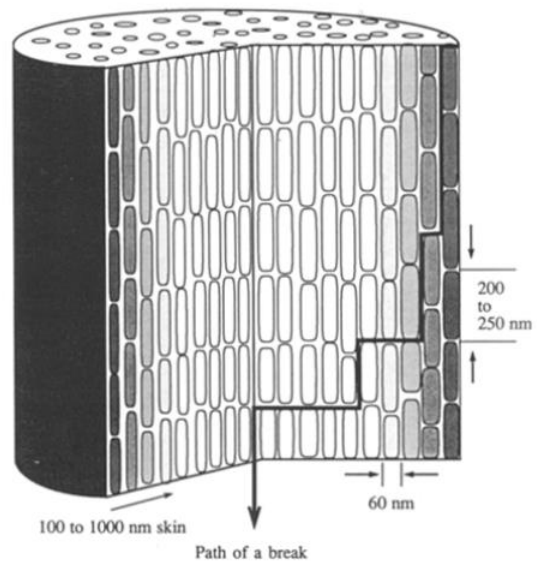

Figure 13: Skin-core morphology of Vectran fibres [33]

Compared to metals (or other polymers such as Dyneema and Spectra), strain hardening is observed on an object when upon reaching its yield stress, the stress-strain curve starts to 
deviate non-linearly, manifesting itself physically as necking - shown schematically in Figure 14 (c). However, in the case of Vectran, necking (shown experimentally in Figure 14 (a) and (b)) is suggested to occur due to the accelerated elongation on the fibre surface, which is an inherent characteristic of the skin-core structure of the fibre - Figure 13. Thus, residual strain can be seen as early as $0.5 \%$ strain upon unloading from a tensile test. Simultaneously, during tensile loading, a further improvement in the fibre's chain orientation may occur as a result of the molecular chains sliding past each other and re-orienting itself forming a new positional ordering [12], therefore accounting for the slope increase seen in Figure 12.

Recently, it was suggested by Sahin et al. [26] that the skin-core interface of Aramid fibres plays a pivotal role towards its tensile strength. This was shown using optical microscopy, whereby upon skin fracture and the beginning of the core 'pull-out' from the skin, the fibre load capacity drops completely to zero, signifying fibre failure. This 'pull-out' mechanism was suggested to be the main load bearing since the pre-existing flaws which were present on the skin surface and the fibre core were too small (in the range of $50-800 \mathrm{~nm}$ ) to initiate failure [26] [27]. Also, since the skin section of the fibre possesses a different structure, and higher tensile stiffness due to the rapid quenching of the outer fibre surface in the coagulation during manufacture. Therefore, the total energy contribution from fibre failure should be a combination of both the elastic and plastic component, given by:

$$
U_{\text {total }}=U_{\text {elastic }}+U_{\text {plastic }}
$$

The elastic and plastic energy component is schematically shown in Figure 15. The plastic energy can be identified from the area enclosing the permanent strain obtained from a cyclic loading-unloading tensile test, while the rest are of the elastic energy. 


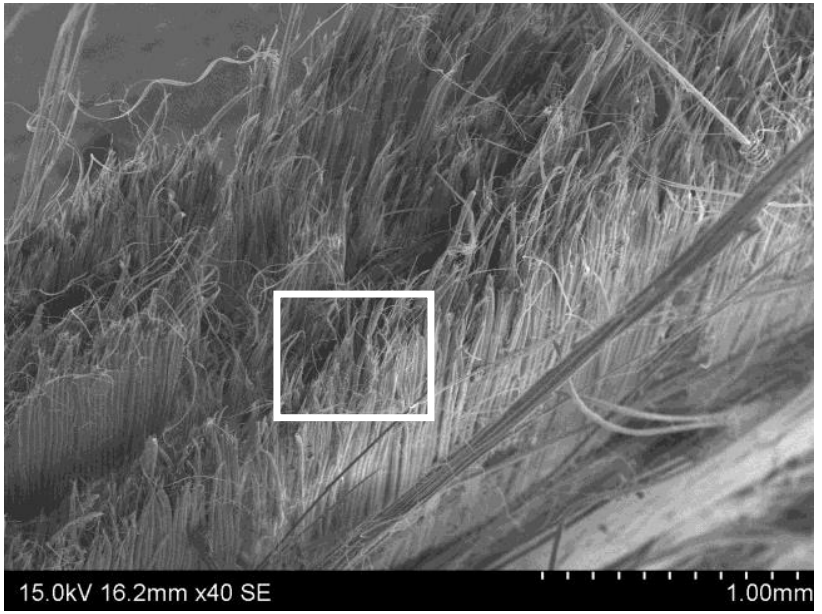

(a)

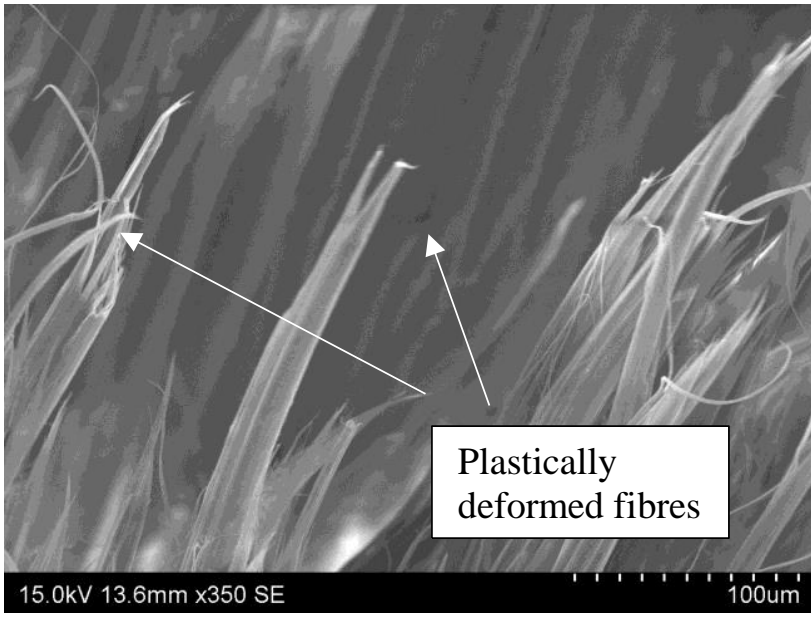

(b)
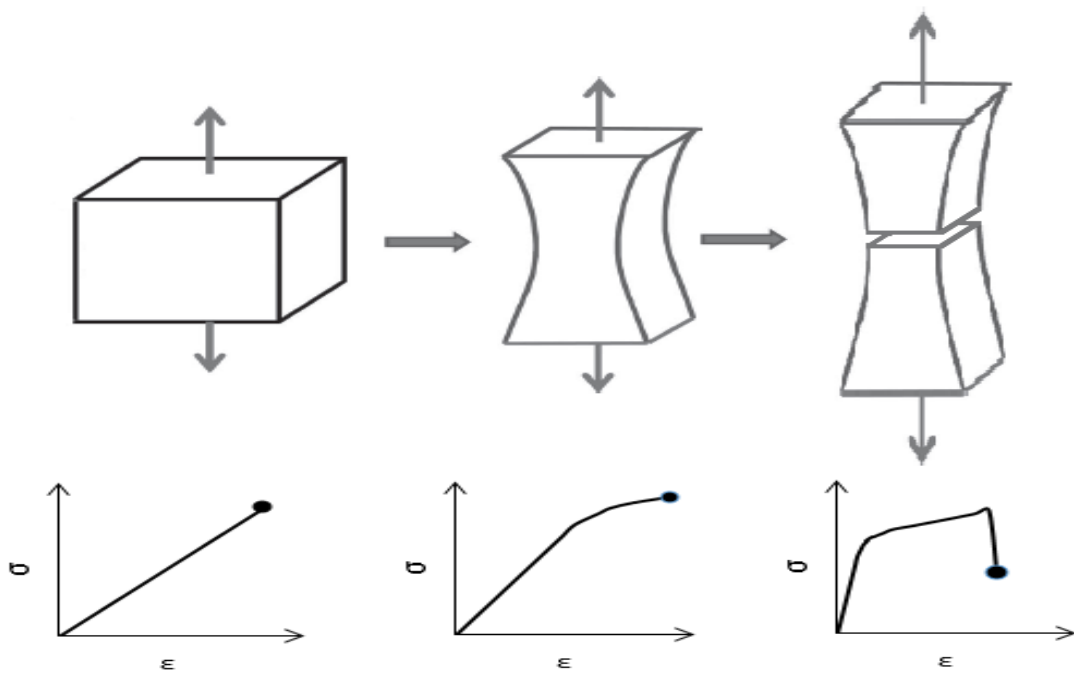

(c)

Figure 14: (a) Vectran fibrils on the CT fracture surface. White square represents close-up image shown in (b). (c) Typical necking phenomenon and its behaviour in the stress-strain curve

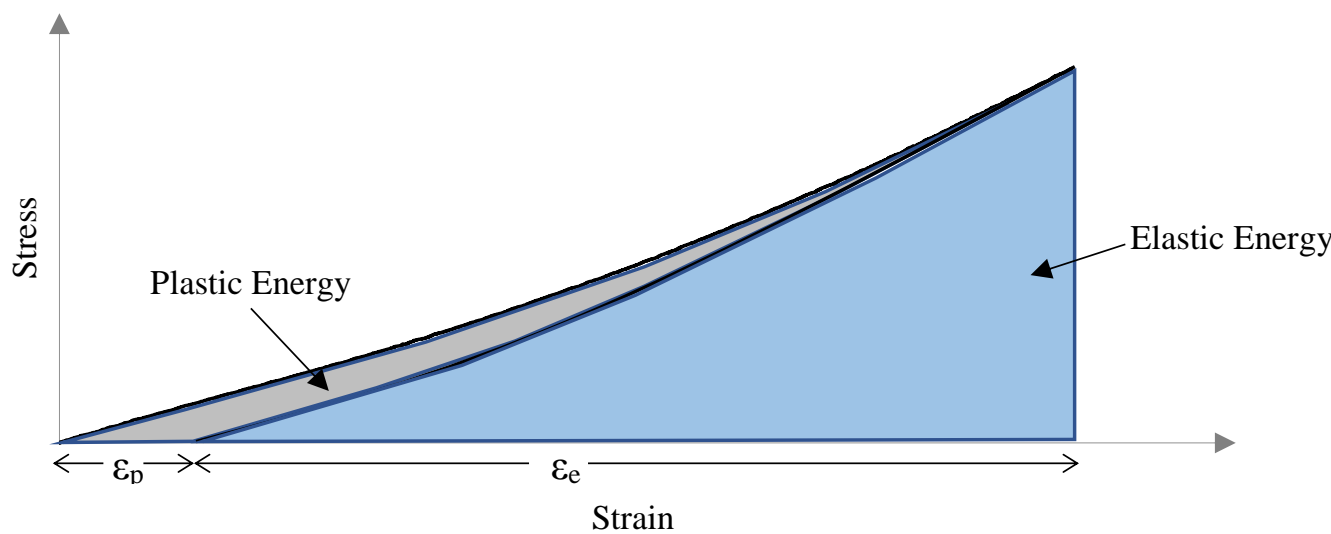

Figure 15: Stress-strain curve of Vectran showing elastic and plastic energy component 
Due to the non-linearity observed in the stress-strain curve, a power law based constitutive equation was proposed to represent the behaviour of Vectran/MTM57 under tensile loading, given by:

$$
\sigma=E\left(\varepsilon^{N}+\varepsilon^{M}\right)
$$

where $E$ was the secant modulus of the stress-strain curve, $M$ and $N$ were constants which can be determined by fitting the expression given in equation (14) on the stress-strain curve. Using equation (14) and representing it in the form of strain energy density (work per unit volume) yields:

$$
U=\int^{\varepsilon} E\left(\varepsilon^{N}+\varepsilon^{M}\right)^{2} d \varepsilon
$$

Using constants obtained by curve-fitting Figure $12(E=37.04 \mathrm{GPa}, N=1.371$ and $M=1.09)$, the total strain energy density was determined to be $11.91 \mathrm{MJ} / \mathrm{m}^{3}$, with the ratio of elastic and plastic contribution were determined to be approximately $89.99 \%$ and $10.01 \%$, respectively.

\subsection{Fibre pull-out}

It was suggested that one of the most significant source of fracture energy is due to interfacial sliding - the case where fibres are 'pulled-out' from its socket in the matrix [6] [2] [15]. This is inclusive of the contribution of shear (sliding) stress between the fibres and the matrices along the length of the fibre. Figure 16 and Figure 17 shows Scanning Electron Microscope (SEM) images of Vectran/MTM57 CT fracture surface. Figure 16 (a) and (b) shows evidence of fibre pull-out, each with varying lengths, seen everywhere on the fracture surface. Consequently, Figure 16 (a) and (b) presents images of shear cusps seen on the fibres, implying a mode II dominated failure have occurred. This may have been due to interfacial sliding, either before (as a result of interfacial debonding) or during fibre pull-out, ultimately contributing to the total fracture energy of Vectran/MTM57. 


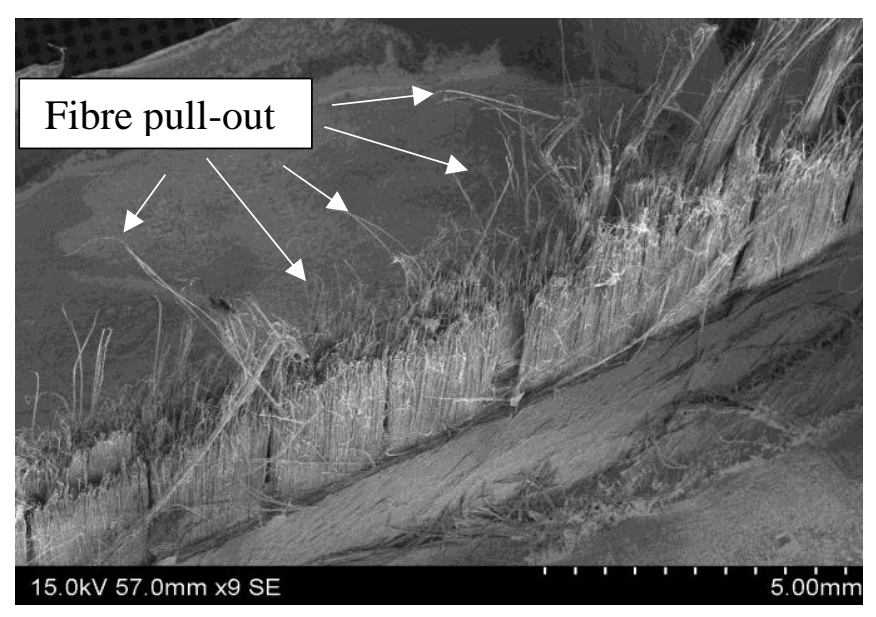

(a)

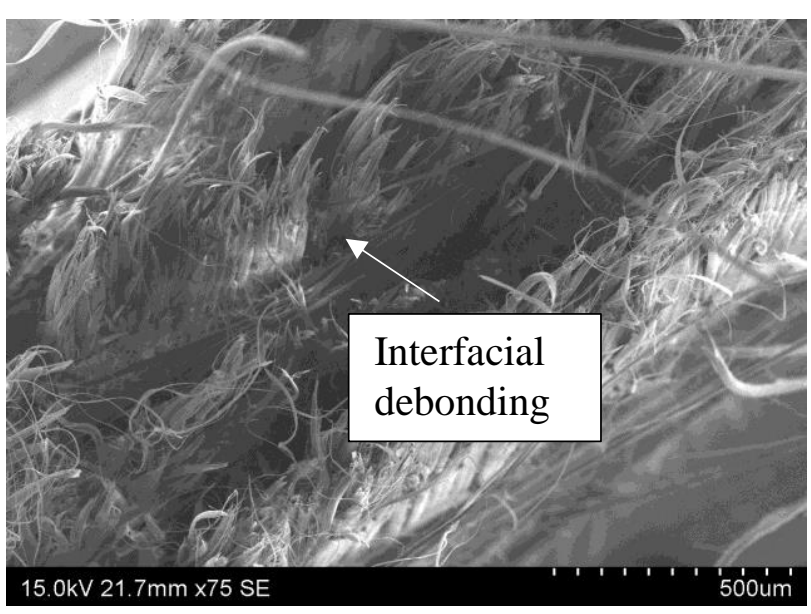

(b)

Figure 16: Evidence of fibre pull-out present on the fracture surface of Vectran/MTM57 CT specimen (a) Fibre pull-out seen on the fracture surface (b) Interfacial debonding between the matrix and the fibres

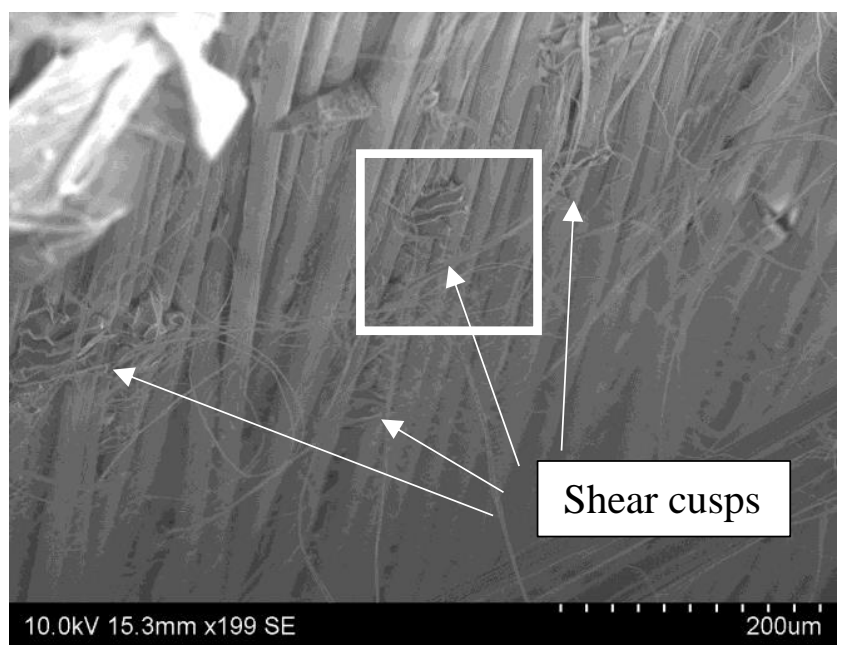

(a)

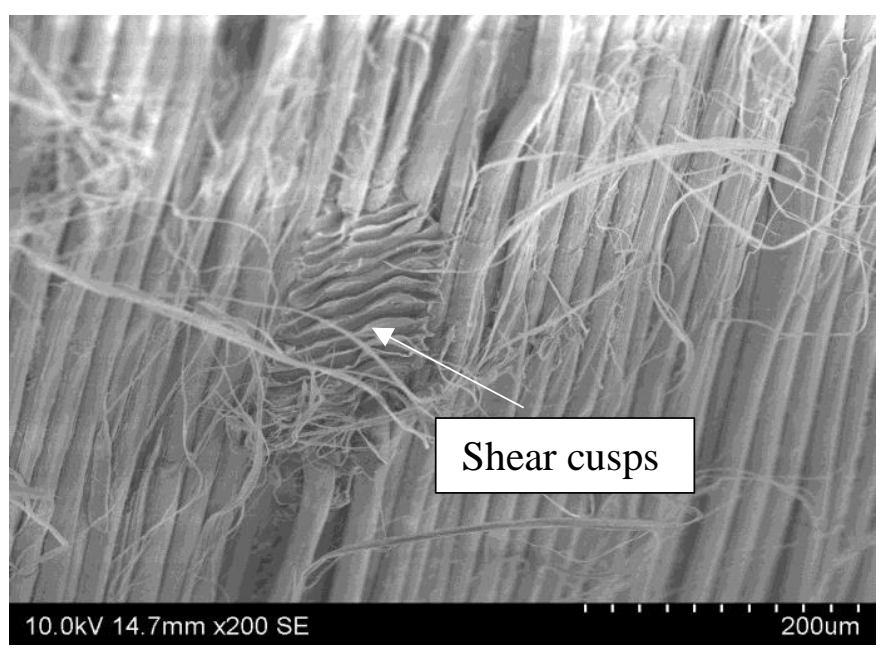

(b)

Figure 17: Evidence of shear cusps on the fibres (a) multiple cusps seen across the fibres. White square represents close-up shown in (b)

The fibre pull-out theory, originally proposed by Kelly et al. [28] takes into account the fibrematrix interfacial shear stress, $\tau_{i}$, is given by [29]:

$$
G_{c p}=\frac{V_{f} \tau_{i} l_{p o}^{2}}{6 d}
$$

where $\tau_{i}$ is the interfacial shear stress and $l_{p o}$ is the fibre pull-out length. However, as observed experimentally, the magnitude of $l_{p o}$ is difficult to determine, as it is randomly dispersed in the laminate. Furthermore, Hull [2] argued that fibre pull-out can only happen in short fibres, as continuous (long) fibres are expected to break in the crack plane, since there will always be 
embedded lengths on either side of the crack plane which are long enough for the stress in the fibre to build up sufficiently to break it. In reality, flaws and defects are often present both in the fibre and the matrix, which naturally will influence the final strength and stiffness of the composite. Therefore, it is possible that these defects could promote fibre fracture inside the matrix, consequently being pulled out from the socket as the crack advances. For this, an estimation can be made for the maximum energy contribution from fibre pull-out, by assuming $l_{p o}$ to be similar to the fibre critical length, $l_{c}$. In general $l_{c}$ is a composite property which can be obtained by performing a single fibre fragmentation test, or can be estimated using the equation below [22]:

$$
l_{c}=\frac{\sigma_{f} d}{2 \tau_{i}}
$$

Therefore, using equation (18) to calculate $l_{c}$ and the information in Table 2, $G_{c p}$ is found to be approximately $30.4 \mathrm{~kJ} / \mathrm{m}^{2}$, implying a significantly higher contribution of energy compared to fibre fracture.

Table 2: Some mechanical properties of Vectran/epoxy composite

\begin{tabular}{cccccc}
\hline $\boldsymbol{\tau}_{\boldsymbol{i}}(\mathrm{MPa})$ & $\boldsymbol{d}(\boldsymbol{\mu m})$ & $\boldsymbol{V}_{\boldsymbol{f}}(\mathbf{\%})$ & $\boldsymbol{l}_{\boldsymbol{c}}(\mathbf{m m})$ & $\sigma_{f}(\mathbf{M P a})$ & $\boldsymbol{\varepsilon}_{\boldsymbol{f}}(\mathbf{\%})$ \\
\hline $19.5[\mathbf{3 0}]$ & 21 & 62 & 0.563 & 1,045 & 2.58
\end{tabular}

\subsection{Fibre bridging phenomenon}

In the wake of the crack growth, broken embedded fibres are said to be pulled-out from the Csockets, leading to a significant amount of energy contribution to the overall fracture energy. This effect is more pronounce when it comes to Vectran fibres. The fibrillar nature of Vectran fibres further promotes fibre bridging, redistributing the stresses that were carried by the broken fibres into the composite thus reducing the stress intensity on the crack tip [22]. Figure 18 shows the development of fibre bridging phenomenon during crack propagation in Vectran/MTM57 CT specimen. It can be seen that the increase in crack growth 
gradually reveals the bridging fibres which originates from the adjacent $90^{\circ}$ plies. The phenomenon can be slightly observed at crack length of approximately $12 \mathrm{~mm}$, and finally fully observable at crack length of $20 \mathrm{~mm}$ - Figure 18 (b). Also seen in the figure are fibre bundles being pulled off in the wake of the crack tip. These observations could suggest the trend seen in the R-curve (Figure 9), in which the R-curve is seen to rise up to crack length of approximately $31 \mathrm{~mm}$, at which the trend is seen to plateau.

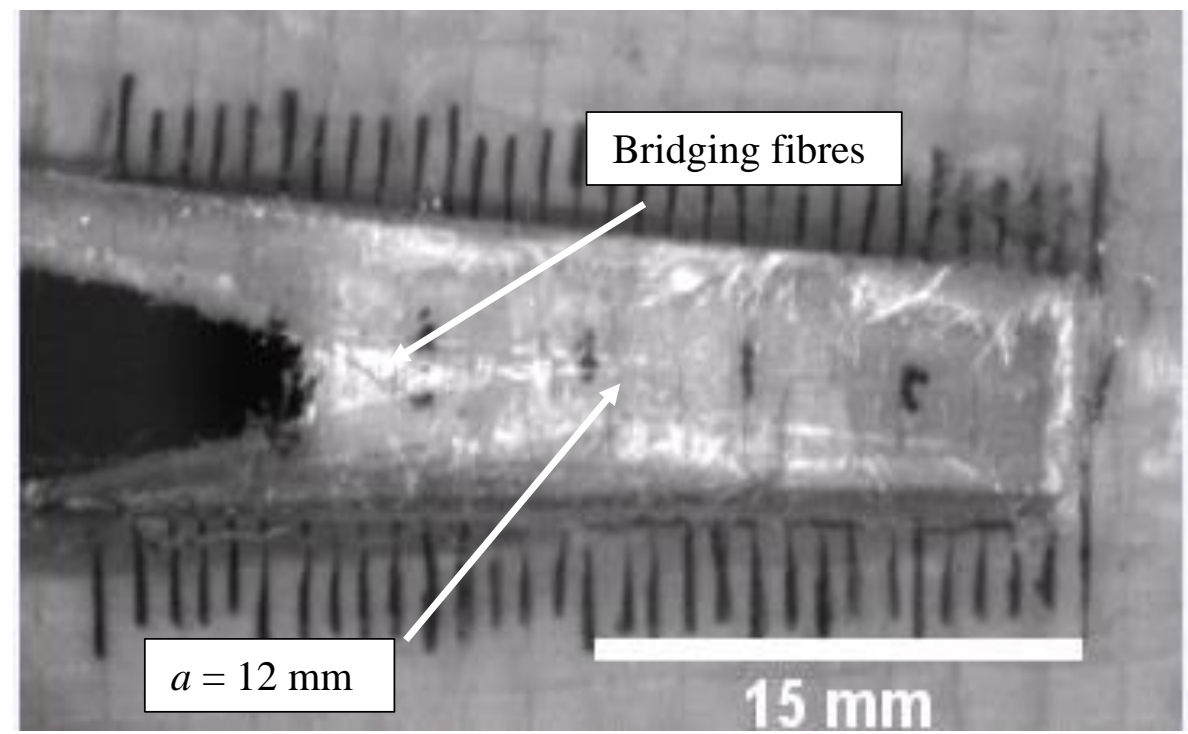

(a)

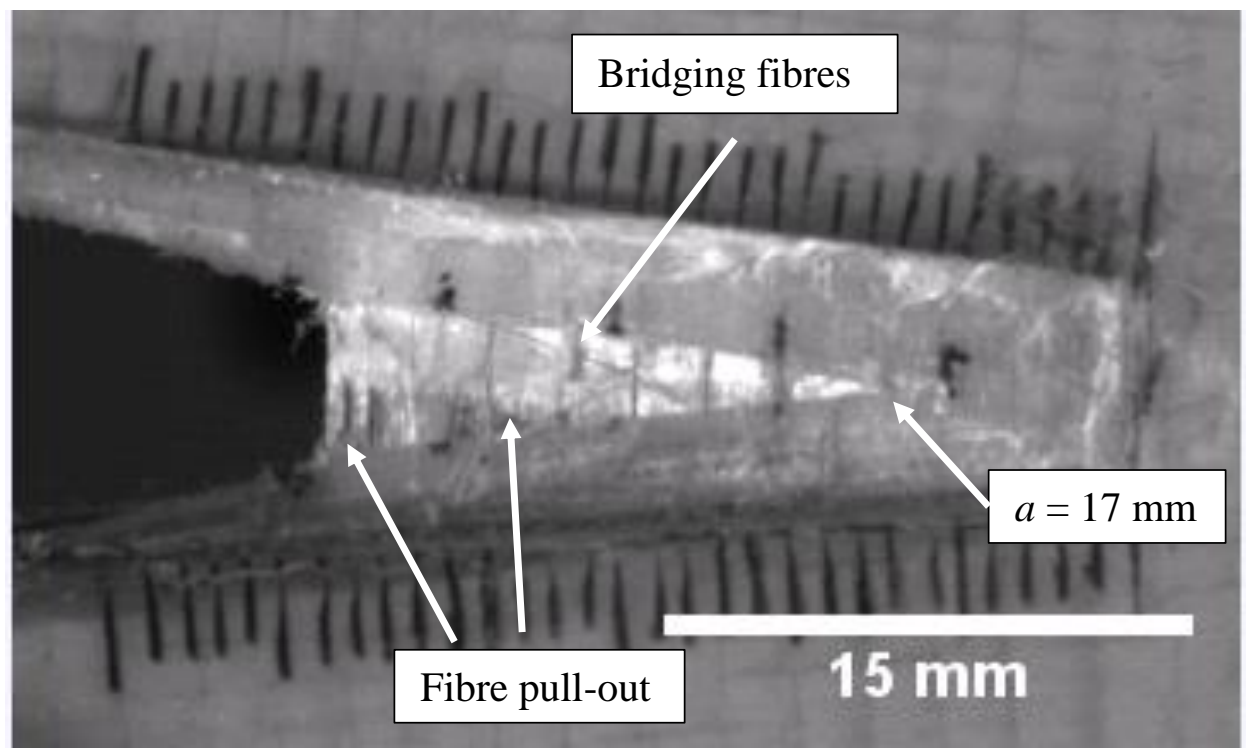

(b)

Figure 18: Fibre bridging development on Vectran/MTM57 CT specimen (a) a=12 mm- Fibre bridging phenomenon can be slightly observed (b) a=17 $\mathrm{mm}$ - Fibre bridging phenomenon fully visible, with evidence of fibre pull-off in the wake of the crack 


\section{Conclusions}

This paper have investigated the translaminar fracture toughness of Vectran/MTM57, as well as the main energy contributing mechanism towards the overall fracture toughness of the composite. It can be concluded that the main energy contribution comes from fibre pull-out, consistent with the works of many researchers when investigating the fracture toughness of the tensile failure modes in laminated composites [5] [7] [8] [11] [31]. It was suggested from previous research that the translaminar fracture toughness of laminated composites is highly influenced by its layup. An increase in the $0^{\circ}$ (often known as ply blocking) fibres will result in a significant increase in the overall fracture energy, due to the increase amount of fibre pullout present [7] [32]. Therefore, it is suggested that a follow up study is to be conducted on Vectran composites to confirm the specimen dependence on the translaminar fracture energies. Finally, the design utilised in this research was found to be reliable in generating a stable crack propagation which is important in the R-curve characterisation. In comparison with the existing designs (which have been discussed in detail by Laffan et al. [5] [9]), the current design employs two thin and thick part, as well as curved edge to which was found to be useful in mitigating compressive failures, which is the 'Achilles heel' of polymer fibre composites. The design could also be 'elongated' to create a longer crack propagation path, therefore obtaining more data points for R-curve characterisation.

\section{Acknowledgements}

The author would like to thank Kuraray for the supply of Vectran NCF fabric, Cytec for the supply of resin film, as well as the assistance of Dr. Nick Fogell, Dr. Frank Gommer, Mr. Atrash Mohsin, Mr. Tomas Katafiasz, Mr. Gary Senior, and Mr. Jonathan Cole in this research. 


\section{Bibliography}

[1] E. S. Greenhalgh, Failure analysis and fractography of polymer composites, Cambridge: Woodhead Publishing in Materials, 2009.

[2] D. Hull and T. W. Clyne, "Toughness of Composites," in An Introduction to Composite Materials, Cambridge, Cambridge University Press, 1996, pp. 218-219.

[3] AGY, "High strength glass fibres," AGY, South Carolina, USA, 2006.

[4] Hexcel corporation, "Hextow IM7 carbon fibre," Hexcel Corporation, Stamford, USA, 2018.

[5] M. J. Laffan, S. Pinho, P. Robinson and A. J. McMillan, "Translaminar fracture toughness testing of composites: A review," Polymer Testing, vol. 31, no. 3, pp. 481489, 2012.

[6] M. J. Laffan, S. T. Pinho, P. Robinson and L. Iannucci, "Measurement of the in situ ply fracture toughness associated with mode I fibre tensile failure in FRP. Part I: Data reduction," Composite Science and Technology, vol. 70, no. 4, pp. 606-613, 2010.

[7] R. F. Teixeira, S. T. Pinho and P. Robinson, "Translaminar ply fracture toughness of advanced composites," in International Conference on Composite Materials (ICCM 18), Jeju Island, South Korea, 2011.

[8] S. T. Pinho, P. Robinson and L. Iannucci, "Fracture toughness of the tensile and compressive fibre failure modes in laminate composites," Composite Science and Technology, pp. 2069-2079, 2006.

[9] M. J. Laffan, S. Pinho, P. Robinson and A. J. McMillan, "Translaminar fracture toughness: The critical notch tip radius of 0 plies in CFRP," Composite Science and Technology, vol. 72, no. 1, pp. 97-102, 2011.

[10] G. Catalanotti, P. Camanho, J. Xavier, C. Davila and A. T. Marques, "Measurement of resistance curves in the longitudinal failure of composites using digital image correlation," Composites Science and Technology, vol. 70, no. 13, pp. 1986-1993, 2010.

[11] G. Bullegas, S. Pinho and S. Pimenta, "Engineering the translaminar fracture behaviour of thin-ply composites," Composites Science and Technology, vol. 131, pp. 110-122, 2016.

[12] A. Donald, A. Windle and S. Hanna, Liquid Crystalline Polymers as Structural Materials, Cambridge: Cambridge University Press, 2006.

[13] D. Gross and T. Seelig, Fracture Mechanics - With an Introduction to Micromechanics, 1 ed., F. F. Ling, Ed., Darmstadt: Springer, 2006.

[14] T. J. Katafiasz, L. Iannucci and E. S. Greenhalgh, "Interlaminar and intralaminar properties of carbon spread tow and glass fibre hybrid composites for cost saving in the mass production of automotive components," in European Conference on Composite Materials (ECCM 17), Munich, Germany, 2016.

[15] Y. Mai and F. Castino, "Fracture toughness of Kevlar-epoxy composites with controlled interfacial bonding," Journal of Material Science, vol. 19, pp. 1638-1655, 1984.

[16] Livermore Software Technology Corporation (LSTC), "www.dynasupport.com/manuals," 26 July 2017. [Online]. Available: www.dynasupport.com/manuals/ls-dyna-manuals/ls-dyna-manual-r10.0-vol-ii. [Accessed 8 August 2017]. 
[17] M. T. Cann, D. O. Adams and C. L. Schneider, "Characterization of Fibre Volume Fraction Gradients in Composite Laminates," Journal of Composite Materials, vol. 42, no. 5, pp. 447-466, 2008.

[18] M. Waterbury and T. D. Lawrence, "Determination of Fibre Volume Fraction by Optical Numerical Volume Fraction Analysis," Journal of Reinforced Plastics and Composites, vol. 8, no. 6, pp. 627-636, 1989.

[19] American Standard for Testing Materials (ASTM), "Standard Test Method for LinearElastic Plane Strain Fracture Toughness Kic of Metallic Materials," ASTM, West Conshocken, PA, 2012.

[20] D. Porter, J. Guan and F. Vollrath, "Spider silk: Super material or thin fibre," Advanced Materials, vol. 25, no. 9, pp. 1275-1279, 2013.

[21] C. Y. Yue and K. Padmanabhan, "Interfacial studies on surface modified Kevlar fibre/epoxy matrix composites," Composites Part B: Engineering, vol. 30, no. 2, pp. 205-217, 1999.

[22] J. K. Kim and Y. W. Mai, "High strength, high fracture toughness fibre composites with interface control - A review," Composites Science and Technology, vol. 41, no. 1991, pp. 333-378, 1991.

[23] J. Kim and Y.-M. Mai, "Effects of interfacial coating and temperature on the fracture behaviours of unidirectional kevlar and carbon fibre reinforced epox composites," Journal of Materials Science, vol. 26, no. 17, pp. 4702-4720, 1991.

[24] A. Pegoretti, A. Zanolli and C. Migliaresi, "Preparation and tensile mechanical properties of unidirectional liquid crystalline single-polymer composites," Composites Science and Technology, vol. 66, no. 13, pp. 1970-1979, 2006.

[25] K. Naito, "Tensile Properties and Weibull Modulus of Some High-Performance Polymeric Fibers," Journal of Applied Polymer Science, vol. 128, no. 2, pp. 1185-1192, 2013.

[26] K. Sahin, J. Clawson, J. Singletary, S. Horner, J. Zheng, A. Pelegri and I. Chasiotis, "Limiting role of crystalline domain on the modulus and strength of aramid fibers," Polymer, p. Article in press, 2018.

[27] K. Strawhecker and D. Cole, "Morphological and local mechanical surface characterization of ballistic fibres via AFM," Journal of Applied Polymer Science, vol. 131 , no. 19, pp. 1-12, 2014.

[28] A. Kelly and W. R. Tyson, "Tensile properties of fibre-reinforced metals: Copper/tungsten and copper/molybdenum," Journal of the mechanics and physics of solids, vol. 13, no. 6, pp. 329-338, 1965.

[29] J.-K. Kim and Y.-W. Mai, "High Strength, High Fracture Toughness Fibre Composites with Interface Control - A review," Composites Science and Technology, vol. 41, no. 1991, pp. 333-378, 1991.

[30] J. Zeng and N. Netravali, "Effects of $\mathrm{XeCl}$ excimer laser treatment of Vectran fibers and their adhesion to epoxy resin," Journal of Adhesion Science and Technology, vol. 20, no. 5, pp. 387-409, 2012.

[31] D. C. Phillips and A. S. Tetelman, "The fracture toughness of fibre compostes," Composites, vol. 3, no. 5, pp. 216-223, 1972.

[32] M. Laffan, S. Pinho, P. Robinson and L. Iannucci, "Fracture toughness measurement for mode I fibre tensile failure in FRP," in International Conference on Composite Materials, Edinburgh, UK, 2009. 
[33] J. Kalantar and J. Drzal, "The bonding mechanism of aramid fibres to epoxy matrices," Journal of Materials Science, vol. 25, no. 10, pp. 4186-4193, 1990. 